T. Irako • T. Akamizu • H. Hosoda $\cdot$ H. Iwakura •

H. Ariyasu $\cdot$ K. Tojo $\cdot$ N. Tajima $\cdot$ K. Kangawa

\title{
Ghrelin prevents development of diabetes at adult age in streptozotocin-treated newborn rats
}

Received: 21 November 2005 / Accepted: 17 January 2006 / Published online: 29 March 2006

(C) Springer-Verlag 2006

\begin{abstract}
Aims/hypothesis: Ghrelin, a stomach-derived hormone, functions in multiple biological processes, including glucose metabolism and cellular differentiation and proliferation. In this study, we examined whether early treatment with ghrelin can regenerate beta cells of the pancreas in an animal model of diabetes mellitus, the n0STZ model, in which neonatal rats are injected with streptozotocin (STZ) at birth. Methods: Following administration of ghrelin to $\mathrm{n} 0-\mathrm{STZ}$ rats from postnatal days 2 to 8 , we examined beta cell mass, mRNA expression levels of insulin and of pancreatic and duodenal homeobox $1(P d x l)$ gene, and pancreatic morphology on days 21 and 70. In addition, we investigated the effects of ghrelin on beta cell replication. Results: By day 21, ghrelin treatment increased pancreatic expression of insulin and $P d x 1$ mRNA in $n 0-S T Z$ rats. The number of replicating cells was also significantly increased in the ghrelin-treated n0-STZ model. At day 70, n0-STZ rats exhibited hyperglycaemia, despite slight increases in
\end{abstract}

T. Irako $\cdot$ T. Akamizu $\cdot$ H. Hosoda $\cdot$ H. Iwakura

H. Ariyasu $\cdot$ K. Kangawa

Ghrelin Research Project, Department of Experimental

Therapeutics, Translational Research Center,

Kyoto University Hospital,

Kyoto University School of Medicine,

Kyoto, Japan

T. Irako $\cdot$ K. Tojo $\cdot$ N. Tajima

Division of Diabetes and Endocrinology,

Department of Internal Medicine,

Jikei University School of Medicine,

Tokyo, Japan

H. Hosoda $\cdot$ K. Kangawa

Department of Biochemistry,

National Cardiovascular Center Research Institute,

Osaka, Japan

T. Akamizu $(\bowtie)$

Translational Research Center, Kyoto University Hospital,

54 Shogoin-Kawaharacho,

Sakyo-ku, Kyoto, 606-8507, Japan

e-mail: akataka@kuhp.kyoto-u.ac.jp

Tel.: +81-75-7514723

Fax: $+81-75-7514731$ plasma insulin levels. Ghrelin treatment resulted in the improvement of plasma glucose levels, which were associated with normal plasma insulin levels. Pancreatic insulin mRNA and protein levels were significantly increased in ghrelin-treated n0-STZ model animals. Conclusions/interpretation: These findings suggest that ghrelin promotes regeneration of beta cells in STZ-treated newborn rats. Thus, early administration of ghrelin may help prevent the development of diabetes in disease-prone subjects after beta cell destruction.

Keywords Diabetes mellitus · Ghrelin · Insulin · Pancreatic beta cell $\cdot \mathrm{Pdx} 1 \cdot$ Streptozotocin

Abbreviations BrdU: 5-bromodeoxyuridine - FBG: fasting blood glucose $\cdot$ GHS-R: growth hormone secretagogue receptor Pdx1: pancreatic and duodenal homeobox $1 \cdot$ STZ: streptozotocin

\section{Introduction}

Ghrelin was originally isolated from rat stomach as a growth-hormone-releasing acylated peptide [1]. This peptide hormone stimulates food intake and growth hormone secretion $[2,3]$, but also plays a regulatory role in glucose metabolism and insulin secretion. Ghrelin may have direct biological action within the pancreas, potentially functioning during pancreatic development. Although these results remain controversial, in vivo peripheral administration of ghrelin modulated plasma insulin and glucose levels [4-7]. The growth hormone secretagogue receptor (GHS-R), for which ghrelin can serve as a ligand, is expressed in the pancreas $[8,9]$. Ghrelin gene expression is markedly higher in the fetal pancreas than in the stomach [10], suggesting ghrelin might be involved in the development, proliferation or differentiation of the pancreas. Ghrelin has been reported to possess mitogenic and anti-apoptotic actions in adipocyte cells; treatment of pre-adipocytes with ghrelin induced cellular proliferation and differentiation into mature adipocytes [11, 12]. 
Diabetes mellitus is a common and serious disease. Of the abundant experimental trials designed to explore novel therapies for the disease, one attempted to increase insulin secretion from the pancreas by promoting the proliferation or regeneration of beta cells [13]. In this study, we examined the effects of ghrelin on the development of hyperglycaemia and the regeneration of beta cells in streptozotocin (STZ)-treated newborn rats, which show rapid remission but gradual development of diabetes in adult animals. This model has been traditionally used to study pancreatic regeneration [14-16]. We investigated the changes in the islets of Langerhans morphology and pancreatic insulin mRNA and protein levels following ghrelin administration in this animal model. Further, we studied the resulting alterations in the expression levels of pancreatic and duodenal homeobox 1 (Pdx1), one of the major pancreatic transcriptional factors thought to play a key role in the development and regeneration of the pancreas [17-19].

\section{Materials and methods}

\section{Animals}

All animal experimental procedures were approved by the Kyoto University Graduate School of Medicine committee on animal research.

Female and male Sprague-Dawley rats, purchased from Charles River (Yokohama, Japan), were allowed free access to tap water and a standard pellet rat diet (352 kcal/100 g, CE-2; Clea, Tokyo, Japan). Females were caged with a male for one night; pregnancy was detected by abdominal palpation 14 days later. Natural birth occurred 22 days after mating.

We examined four experimental groups: (1) a Control group, in which newborn rats received a single i.p. injection of citrate buffer; (2) a Ghrelin group, which received twice daily s.c. injections of ghrelin $(100 \mu \mathrm{g} / \mathrm{kg}$ body weight) for 7 days (from day 2 to 8) after birth; (3) an n0-STZ group, which received a single i.p. injection of streptozotocin; and (4) an n0-STZ/Ghrelin group, which received a single i.p. injection of streptozotocin followed by injections of ghrelin as in the Ghrelin group. Dams were randomly assigned to four groups and pups from the same litter were assigned to the same group. The numbers of dams in each of the four groups were five (Control), five (Ghrelin), seven (n0-STZ) and seven (n0-STZ/Ghrelin).

At birth, newborns received a single i.p. injection of $100 \mathrm{mg} / \mathrm{kg}$ body weight of STZ (Sigma, Steinheim, Germany), freshly dissolved in citrate buffer $(0.05 \mathrm{mmol} / \mathrm{l}$, $\mathrm{pH}$ 4.5). Pups were left with their mothers. All neonates were tested on day 2 for glycosuria with Multistix SG (Bayer Medical, Leverkusen, Germany). Only those animals that were glycosuric (3+ value with the Multistix SG test) at day 2 after birth were included in the n0-STZ model group. Ghrelin treatment was started after glycosuria was confirmed.
Animals were killed at 21 or 70 days after birth by bleeding following anaesthesia with an i.p. injection of sodium pentobarbital $(50 \mathrm{mg} / \mathrm{kg})$. Blood samples were collected from the inferior vena cava, centrifuged immediately at $20,000 \times \mathrm{g}$ for $2 \mathrm{~min}$ at $4^{\circ} \mathrm{C}$, and stored at $-80^{\circ} \mathrm{C}$ until assayed.

\section{Pancreas removal and treatment}

After excision, pancreases were removed and weighed. To measure insulin content, pancreases (35-50 mg) were homogenised and centrifuged in $5 \mathrm{ml}$ acid-ethanol $(0.15 \mathrm{~mol} / 1 \mathrm{HCl}$ in $75 \%$ [vol $/ \mathrm{vol}]$ ethanol $)$ at $1,000 \mathrm{~g}$ for $20 \mathrm{~min}$; the supernatants were stored at $-80^{\circ} \mathrm{C}$. For immunohistochemistry, additional pancreases were fixed in $4 \%$ paraformaldehyde fixative for $24 \mathrm{~h}$ and embedded in paraffin.

\section{Immunohistochemistry}

Insulin and Pdx1 were detected immunohistochemically on 3 - $\mu \mathrm{m}$-thick tissue sections using an indirect peroxidaselabelling technique. Sections were incubated for $1 \mathrm{~h}$ at room temperature or overnight at $4{ }^{\circ} \mathrm{C}$ with primary antibodies (guinea-pig anti-porcine insulin [Dako, Glostrup, Denmark], or rabbit anti-mouse/rat IDX-1 [Chemicon, Temecula, USA]). Insulin- and Pdx1-positive staining was visualised using a 3,3'-diaminobenzidine tetrahydrochloride kit (DakoCytomation) and fluorescence, respectively. Quantitative evaluations of insulin- and Pdx1-positive areas were performed using a computer-assisted image analysis procedure using an Olympus BX 51 microscope connected via a DP 12 digital camera and Mac SCOPE Ver 2.6 software (Mitani, Fukui, Japan). The insulin- and Pdx1-positive area, as well as the area of the total pancreatic section, was evaluated on ten non-consecutive sections of the pancreas of five animals per group at each point. For semi-quantitative analysis, more than six fields were observed per section. The relative volume of insulin- and Pdx1-positive cells was determined by a stereological morphometric method, calculating the ratio between the areas occupied by immunoreactive cells and that occupied by total pancreatic cells.

\section{Beta cell replication}

Pancreatic sections that had not already been used for morphometric studies were used to examine beta cell replication. Sections were double-stained for phosphohistone H3 (Ser10) and insulin. Sections were incubated with a 1/50 dilution of anti-phospho-histone H3 (Ser10) antibody (Cell Signaling Technology, Beverly, MA, USA) overnight at $4^{\circ} \mathrm{C}$. Sections were then incubated with guinea-pig anti-insulin antibody for $1 \mathrm{~h}$ at room temperature. After six washes with PBS, the sections were incubated with the secondary antibody conjugated with fluorescence (Alexa fluor 488 and 546; Molecular Probes, 
Eugene, OR, USA) in blocking solution for $30 \mathrm{~min}$ at room temperature. After rinsing with PBS, sections were mounted with Mounting Medium with DAPI (Vector Laboratories, Burlingame, CA, USA) and examined with confocal laser scanning microscopy (Leica Microsystems, Mannheim, Germany). A minimum of 1,000 beta cell nuclei were counted per section.

RNA extraction and RT-PCR methods

Total RNA was extracted from rat pancreases as previously described [20]. To synthesise the first-strand cDNA, the extracted products were used as templates in reactions containing RT (Invitrogen, Carlsbad, CA, USA). RT-PCR analysis was performed as previously described [20]. The first-strand cDNA was used in subsequent PCR analyses, in combination with the following oligonucleotide primers: insulin-1: 5' TAGACCATCAGCAAGCAGGTC, 3' CAC ACCAGGTACAGAGCCT; $P d x 1$ : 5' AGGAGGTGCAT ACGCAGCAG, 3' GAGGCCGGGAGATGTATTTGTT.

The identity of the PCR products was confirmed by agarose gel electrophoresis.

\section{Real-time PCR}

We mixed $1 \mu \mathrm{l}$ of the amplified cDNA with $25 \mu \mathrm{l} 2 \times \mathrm{PCR}$ Master Mix (Applied Biosystems, Foster City, CA, USA), $23 \mu \mathrm{l}$ sterile distilled water and $0.5 \mu \mathrm{l} 10 \mathrm{pmol} / \mu \mathrm{l}$ sense and antisense primers specific for either insulin or $P d x 1$. Forty cycles of PCR amplification were carried out using the Thermal Cycler System (ABI PRISM 7700; Applied Biosystems) for $15 \mathrm{~s}$ at $95^{\circ} \mathrm{C}$ followed by $60 \mathrm{~s}$ at $60^{\circ} \mathrm{C}$. The concentration of each mRNA product was quantified using calibration curves expressing the fluorescence intensity against the amount of standardised PCR product. All expression data were normalised to the amount of $18 \mathrm{~S}$ ribosomal RNA (Applied Biosystems) amplified from the same individual sample.

\section{Analytical techniques}

Plasma and blood glucose levels were determined using a glucose analyser (Antisense 2; Sankyo, Tokyo, Japan). Insulin was extracted from pancreases as described [21].
Insulin concentrations were measured using a Lebis insulin ELISA kit (Shibayagi, Gunma, Japan).

Statistical analysis

Values are expressed as means \pm SEM. Differences between each group of rats were evaluated using a Mann-Whitney test or a Bonferroni-corrected ANOVA as appropriate. A value of $p<0.05$ was considered statistically significant.

\section{Results}

Effects of ghrelin treatment from day 2 to day 8 after birth: studies on day 21

The characteristics of the 21-day-old rats are summarised in Table 1. After screening n0-STZ and n0-STZ/Ghrelin groups for glucosuria (3+ or more) on day 2 after birth, animals were kept for an additional 19 days. While significant changes in body weight and fasting blood glucose (FBG) levels were observed between the Control and Ghrelin groups, no changes in these parameters and insulin levels were observed between the $\mathrm{n} 0-\mathrm{STZ}$ and $\mathrm{n} 0$ STZ/Ghrelin groups (Table 1). There were no significant differences in body weight, FBG levels and insulin levels between the Control and n0-STZ groups or between the Ghrelin and n0-STZ/Ghrelin groups, although a significant change in FBG levels was observed between the Control and $\mathrm{n} 0-\mathrm{STZ} / \mathrm{Ghrelin}$ groups.

Insulin mRNA expression levels within the pancreas were markedly reduced in the n0-STZ group in comparison with Control animals. These levels, however, returned to levels similar to those of the Control group following ghrelin treatment (n0-STZ/Ghrelin group) (Fig. 1a). The pancreatic insulin mRNA expression level of the n0-STZ group was approximately one-third of those of the Control and n0-STZ/Ghrelin groups. In addition, insulin immunostaining of the pancreas was reduced to approximately onetwentieth compared with that of the Control group (Fig. 1b-f). These finding are surprising, because the $n 0$ STZ group exhibited plasma insulin levels similar to those of the Control and n0-STZ/Ghrelin groups. Therefore, they suggested that neonatal beta cells, even if the number becomes small, are able to secrete insulin to keep the plasma level normal.

Table 1 Characteristics (means \pm SEM) of fasted 21-day-old rats

\begin{tabular}{lcccc}
\hline & Control & Ghrelin & n0-STZ & n0-STZ/Ghrelin \\
\hline Body weight (g) & $37.8 \pm 1.1(20)$ & $45.1 \pm 0.8(8)^{*}$ & $37.6 \pm 1.2(15)$ & $36.3 \pm 1.3(9)$ \\
FBG (mmol/l) & $6.3 \pm 0.1(17)$ & $5.2 \pm 0.3(8)^{* *}$ & $5.9 \pm 0.2(15)$ & $5.6 \pm 0.1(8)^{* * *}$ \\
Plasma insulin (pmol/l) & $55 \pm 6(7)$ & $41 \pm 5(8)$ & $55 \pm 13(6)$ & $60 \pm 2(6)$ \\
\hline
\end{tabular}

Number of rats in parentheses

Statistical analysis (Mann-Whitney test) was carried out between all groups

${ }^{*} p<0.005, * * p<0.0005, * * * p<0.05$ (vs Control) 
Fig. 1 Gene expression levels (a) and immunostaining (b-f) of insulin in the pancreases of 21day-old n0-STZ and n0-STZ/ Ghrelin animals. b Quantification of insulin-positive cells per unit of total tissue area; c Control group; d Ghrelin group; e n0-STZ group; f n0-STZ/ Ghrelin group. Cont Control group, $G$ Ghrelin group, $S T Z$ n0-STZ group, $S T Z+G$ n0-STZ/ Ghrelin group. Values are expressed as means \pm SEM for four observations in each group. ${ }^{*} p<0.001 ; * * p<0.005$ ( $n=6-8$ rats). In $\mathbf{c}-\mathbf{f}$, original magnifications were $\times 100$ a

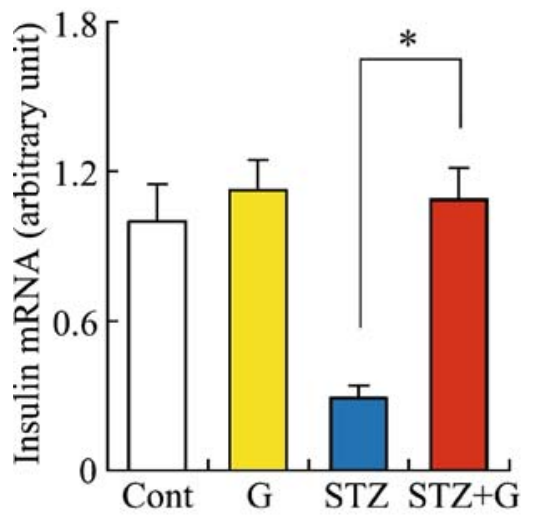

C

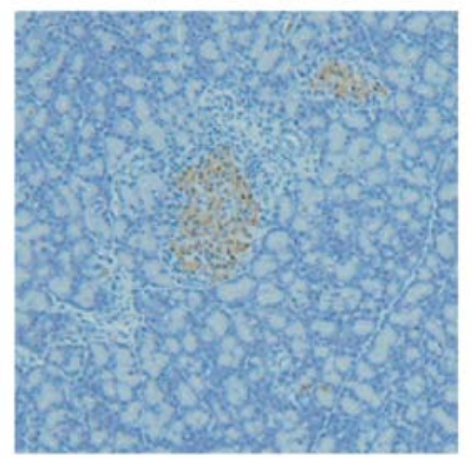

e

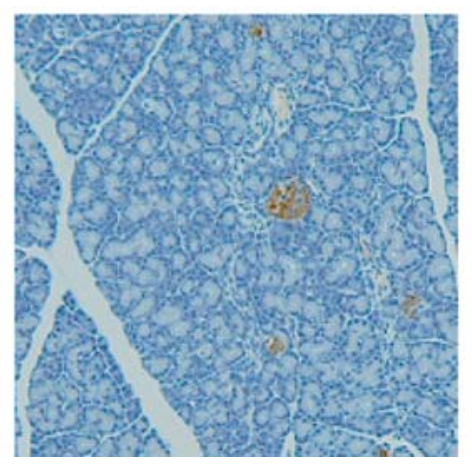

b

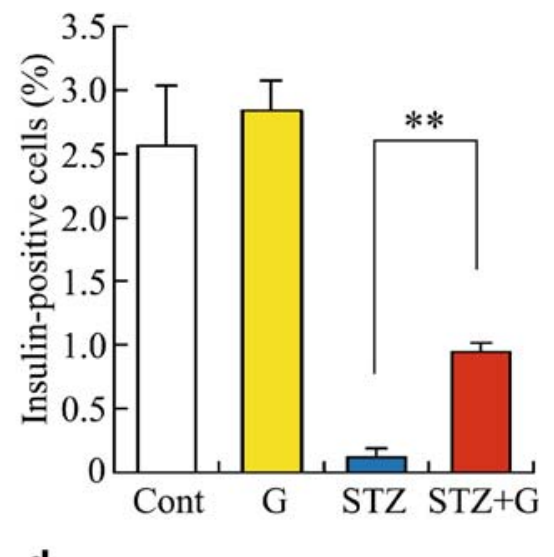

d

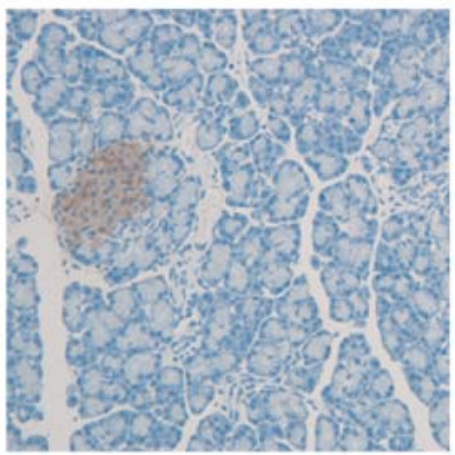

f

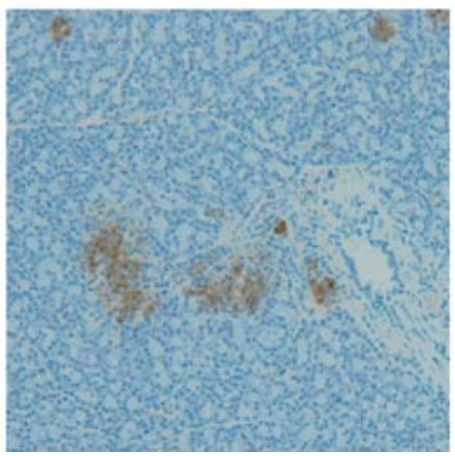

To explore the mechanism governing the alteration of insulin expression in the pancreas, we examined the expression of Pdx1, one of the major transcriptional factors involved in pancreatic development. $P d x 1$ mRNA levels changed in a manner similar to those of insulin except for the Ghrelin group (Fig. 2a-f). The expression levels of the gene encoding Pdx 1 in the Ghrelin group was higher than that of the Control (Fig. 2a). $P d x 1$ expression levels in the n0-STZ group were less than one-tenth of the Control group levels; those of the n0-STZ/Ghrelin group returned to levels similar to those seen in the Control group. Immunofluorescence staining for $\mathrm{Pdx} 1$ within the pancreas exhibited a similar pattern to that of insulin in the n0-STZ and $\mathrm{n} 0-\mathrm{STZ} /$ Ghrelin groups (Fig. 2b-f). Corresponding to the change in $P d x 1$ mRNA, the area of Pdx-1-positive cells in the Ghrelin group was significantly increased compared with that in the Control group.
Thus, the n0-STZ group exhibited diminished insulin production at 21 days after birth, although FBG levels achieved a spontaneous remission. The n0-STZ/Ghrelin group showed increased insulin expression in both mRNA and protein levels, Therefore, neonatal ghrelin treatment in this model may improve the reduction of insulin production at 21 days and prevent development of hyperglycaemia at 70 days.

Furthermore, to examine whether beta cell proliferation contributed to ghrelin effects on insulin production and beta cell number in STZ-treated rats or not, we performed phospho-histone H3 immunohistochemical analysis (Fig. 3a). Phospho-histone $\mathrm{H} 3$ is a cell proliferation mitosis marker [22, 23]. In 21-day-old rats, ghrelin treatment increased cells double-positive for phospho-histone $\mathrm{H} 3$ and insulin approximately 1.7- and 15-fold in Ghrelin and n0- 
Fig. 2 Gene expression levels (a) and immunostaining (b-f) of Pdx 1 in the pancreases of 21day-old n0-STZ and n0-STZ/ Ghrelin animals. b Quantification of Pdx1-positive cells per unit of total tissue area; c Control group; d Ghrelin group; e n0-STZ group; f n0-STZ/ Ghrelin group. Cont Control group, $G$ Ghrelin group, $S T Z$ n0-STZ group, $S T Z+G$ n0-STZ/ Ghrelin group. Values are expressed as means \pm SEM for four observations in each group. In $\mathbf{c}-\mathbf{f}$, original magnifications were $\times 500 . * p<0.05$; $* * p<0.001 ; * * * p<0.0001$ $(n=6-8$ rats $)$ a

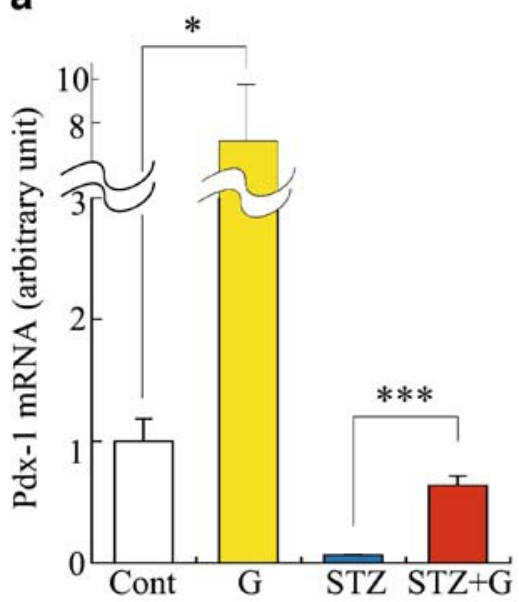

C

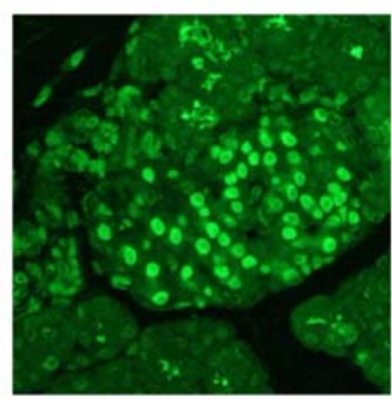

e

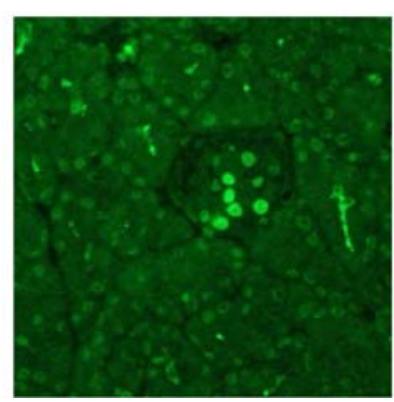

b

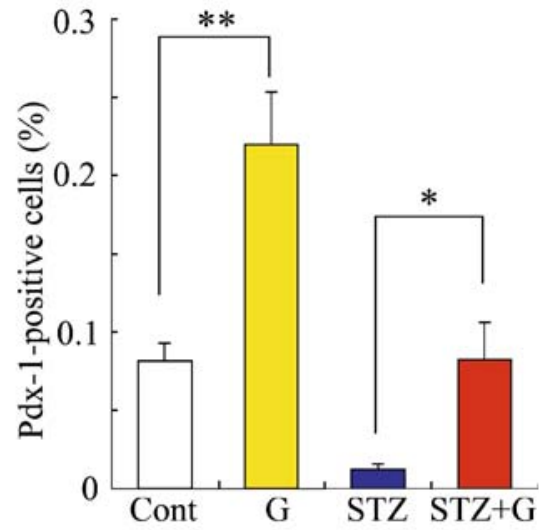

d

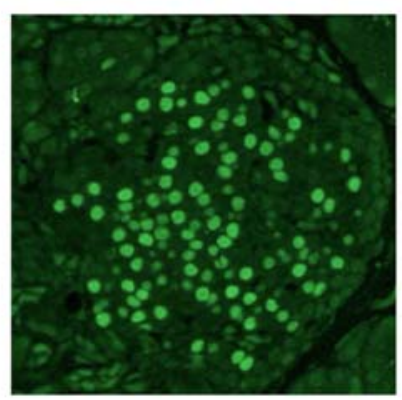

f

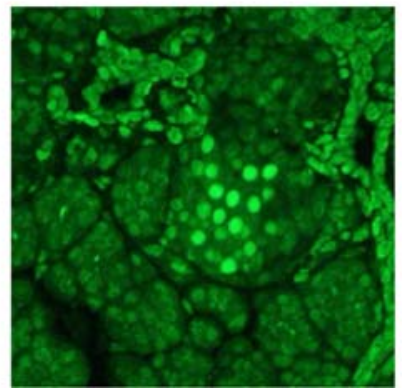

STZ/Ghrelin groups in comparison with Control and n0STZ rats, respectively (Fig. 3b).

Long-lasting effects of early treatment with ghrelin: studies at 10 weeks

As the n0-STZ model develops hyperglycaemia after 810 weeks [14], we examined the long-term effects of early treatment with ghrelin in this model. The characteristics of Control, Ghrelin, n0-STZ and n0-STZ/Ghrelin animals at 10 weeks are detailed in Table 2. As expected, the n0-STZ group demonstrated reduced body weight and hyperglycaemia. Although the plasma insulin levels of this group were not decreased but tended to be slightly increased, the levels for each rat appeared to be relatively low for elevated glucose levels (Table 2, Fig. 4a). In fact, the pancreatic insulin levels of the n0-STZ group were reduced from those of the Control (Table 2). In contrast, the FBG levels of n0STZ/Ghrelin group animals, which were not significantly higher than those of the Control, were significantly lower than those of the n0-STZ group. Furthermore, the pancreatic insulin levels of the n0-STZ/Ghrelin group returned to levels similar to those of the Control group. Body weight of the n0-STZ/Ghrelin group was significantly lower than that of the Control group, but not that of the n0-STZ group.

The mRNA expression of insulin at the adult stage in the Ghrelin group was lower than that in the Control group (Fig. 4b). In the n0-STZ group, the mRNA expression of insulin at day 70 remained reduced. The n0-STZ/Ghrelin group demonstrated a similar insulin expression level to that of the Control group, as was also observed 21 days after birth (Fig. 1a and Fig. 4b).

The patterns of mRNA expression for Pdx-1 in the four groups except the Ghrelin group were similar to those observed 21 days after birth (Fig. 5a). The expression level 
Fig. 3 Examination of beta cell proliferation by phosphohistone $\mathrm{H} 3$ staining in rats. a $\mathrm{A}$ representative confocal image of phospho-histone H3 (green) and insulin (red) immunostaining in an n0-STZ/Ghrelin rat. Phospho-histone H3 labelling index of the beta cell in 21-day-old (b) and 70-day-old (c) rats. It was evaluated through quantification of phospho-histone H3-positive cells in the 1,000 insulin-positive cells. Cont Control group, $G$ Ghrelin group, $S T Z$ n0-STZ group, $S T Z+G$ n0-STZ/Ghrelin group. Values are expressed as means \pm SEM for four observations in each group. Original magnifications were $\times 400$. Bar: $75 \mu \mathrm{m}$. ${ }^{*} p<0.01$ ( $n=5-8$ rats) a

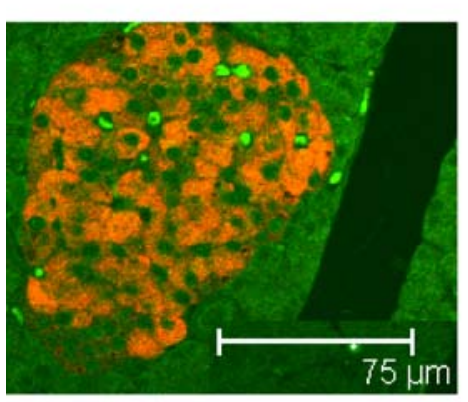

C

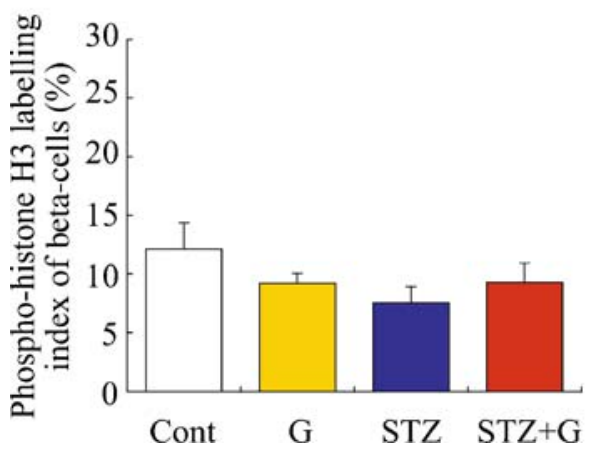

b

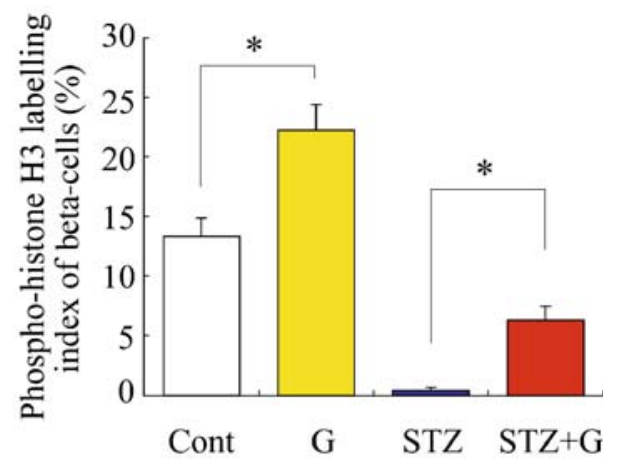

of $P d x 1$ in the Ghrelin group was similar to that of the Control (Fig. 5a). Pdxl gene expression in the n0-STZ group was approximately one-third that of the Control, while that in the n0-STZ/Ghrelin group returned to levels close to that of the Control group. In immunofluorescent staining for Pdx-1 in the pancreas, the increase in staining of the n0-STZ/Ghrelin group was not significant compared with the n0-STZ group, although the Ghrelin group exhibited a significant increase compared with the Control group. (Fig. 5a-e).

We performed the experiments of immunostaining for phospho-histone $\mathrm{H} 3$ and insulin also in the adult stage. There were no significant differences between the four groups. But in the model of STZ, the ghrelin treatment tended to increase the double-positive cells for phosphohistone $\mathrm{H} 3$ and insulin, while in the Control group, the ghrelin treatment tended to decrease those cells (Fig. 3c).

Thus, in this n0-STZ model of diabetes, animals developed reduced insulin production in the pancreas and hyperglycaemia at 10 weeks after birth. Ghrelin treatment may prevent this deterioration through maintenance of insulin-positive cells and insulin production, which mechanistically may involve the increased expression of Pdx1.

\section{Discussion}

Neonatal rats treated with STZ exhibit normal glycaemia at 3 weeks after birth by rapid remission, but then deteriorate gradually after 8 weeks [14-16]. This delayed deterioration probably follows from the inability of the insulin production of the pancreas to recover to the levels of control rats $[14,15]$. In this study, we observed a similar clinical course, characterised by the reduction of insulin production and content in the pancreases of n0-STZ rats. This neonatal model showed more reduction of pancreatic beta cells compared with other reports, in which the

Table 2 Characteristics (means \pm SEM) of fasted rats at 70 days

\begin{tabular}{|c|c|c|c|c|}
\hline & Control & Ghrelin & n0-STZ & n0-STZ/Ghrelin \\
\hline Body weight (g) & $317 \pm 6(6)$ & $364 \pm 22(8)$ & $285 \pm 8(5)$ & $248 \pm 11(13)^{*}$ \\
\hline FBG (mmol/l) & $5.7 \pm 0.4(6)$ & $6.9 \pm 0.4(8)$ & $11.8 \pm 0.3(5)^{* *}$ & $7.6 \pm 0.4(13)^{\dagger}$ \\
\hline Plasma insulin (pmol/1) & $181 \pm 17(6)$ & $207 \pm 15(6)$ & $302 \pm 68(5)$ & $160 \pm 30(8)$ \\
\hline Pancreas weight (mg) & $414 \pm 33(6)$ & $491 \pm 16(6)$ & $520 \pm 42(5)$ & $556 \pm 23(13)$ \\
\hline Pancreatic insulin ( $\mu \mathrm{g} /$ pancreas) & $78.6 \pm 7.8(6)$ & $99.6 \pm 6.0(6)$ & $39.6 \pm 14.1(5)$ & $92.6 \pm 2.4(8)^{\dagger \dagger}$ \\
\hline
\end{tabular}

Statistical analysis (Mann-Whitney test) was carried out between all groups ${ }^{*} p<0.05, * * p<0.0005$ (vs. Control) $p<0.0005,{ }^{\dagger} p<0.05$ (vs. n0-STZ) 
a

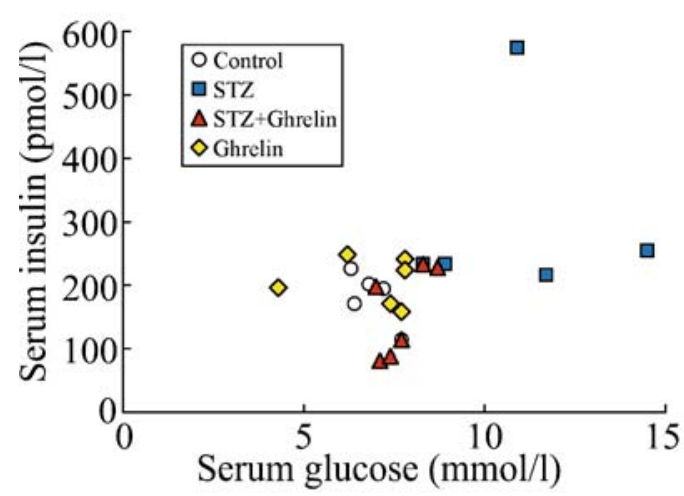

d

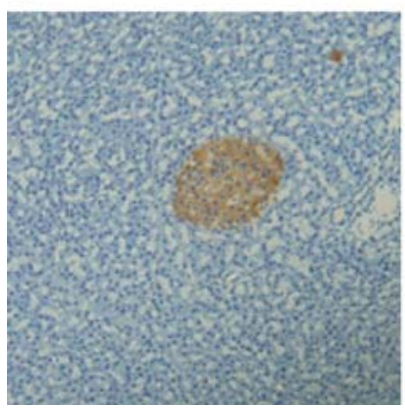

e

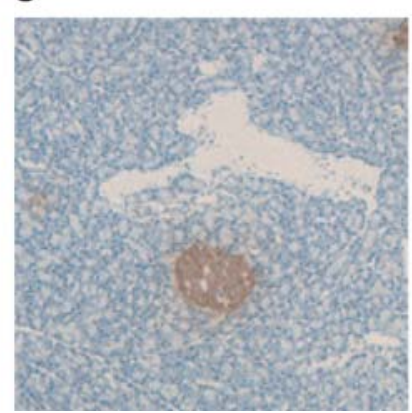

Fig. 4 a Relationship between serum glucose and insulin concentrations in adult animals following fasting. Gene expression levels (b) and immunostaining (c-g) of insulin in the pancreases of adult rats. c Quantification of insulin-positive cells, as performed in Fig. 1b; d Control group; e Ghrelin group; f n0-STZ group; $\mathbf{g}$ n0-

reduction was approximately $50 \%$ that of controls $[15,16$, 24]. This may be due to the different timing of STZ injection, which is known to result in type 2 diabetes models with different severity [14]. In fact, we injected STZ at $24 \mathrm{~h}$ after birth, while others injected within $12 \mathrm{~h}$ of birth $[15,16,24]$.

Moreover, we first demonstrated that ghrelin treatment prevented the development of hyperglycaemia in $\mathrm{n} 0-\mathrm{STZ}$ rats at adult ages. In n0-STZ/Ghrelin rats, both the transcription and translation of insulin in the pancreas were significantly increased at 21 and at 70 days. In addition, Pdx1 gene and protein expression levels at 21 days were restored to levels similar to those of the Control group. These findings strongly suggest that beta cells damaged by STZ administration during the neonatal stage can be regenerated or replicated following ghrelin treatment. Indeed, the immunohistochemical analysis for phospho-histone $\mathrm{H} 3$, which is a proliferation marker, demonstrated that ghrelin treatment significantly increased the staining in both Control and STZ-treated rats at the age of 21 days.

Similar findings have been reported for glucagon-like peptide- 1 and exendin- 4 by Tourrel et al. [13]. They demonstrated that glucagon-like peptide- 1 and exendin- 4 stimulated beta cell neogenesis or regeneration in STZtreated newborn rats. While these n0-STZ rats ameliorated plasma glucose levels at adult stages, such treatment could not improve insulin secretion during a glucose-tolerance

\section{C}

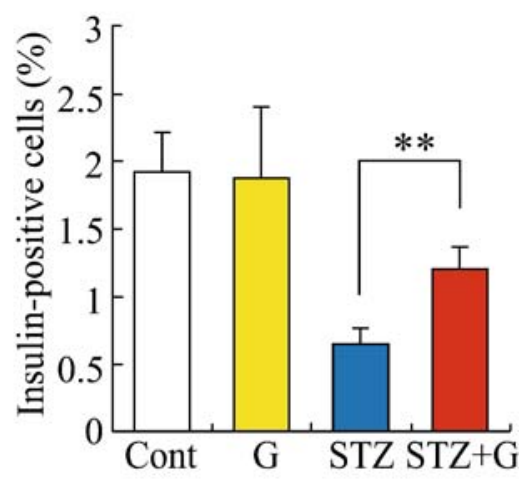

f

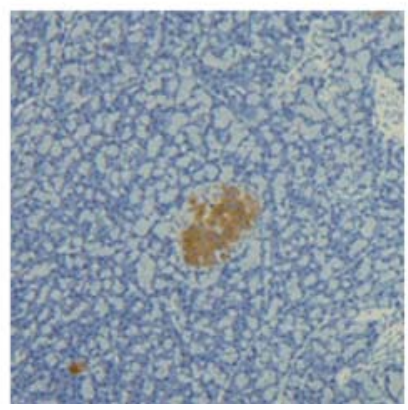

g

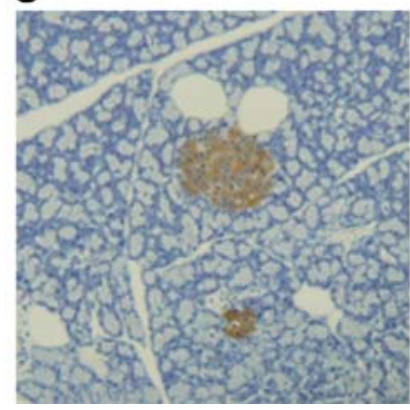

STZ/Ghrelin group. Cont Control group, $G$ Ghrelin group, $S T Z$ n0$\mathrm{STZ}$ group, $S T Z+G \mathrm{n} 0-\mathrm{STZ} / \mathrm{Ghrelin}$ group. Values are expressed as means \pm SEM for four observations in each group. ${ }^{*} p<0.005$ $* * p<0.05$ ( $n=5-8$ rats). In $\mathbf{d}-\mathbf{g}$, original magnifications were $\times 100$

test. In future, it will be necessary to examine the effects of ghrelin treatment on insulin secretion in this n0-STZ/ ghrelin model in detail, including an examination of glucose tolerance. In addition, a possibility that ghrelin treatment might modulate STZ toxic effects should be considered, because ghrelin administration was performed shortly after STZ treatment. Finally, another possibility that STZ may have affected hepatic metabolism and/or insulin sensitivity in peripheral tissues should be taken in account. These effects could explain some of the discrepancies between pancreas and plasma insulin levels.

Several reports have shown that both ghrelin and GHS-R are expressed in the pancreas [8,9, 25-27]. Ghrelin is expressed in both the alpha [28] and beta [9,29] cells of the pancreas. Recently, ghrelin was also identified in epsilon cells [30]. The pancreas is one of the organs in which GHS-R expression has been detected by RNA protection assay [8]. In addition, ghrelin gene expression is higher in the fetal pancreas than in fetal stomach [10], while expression is highest in the stomach in adults. Thus, ghrelin may act on beta cells in a paracrine or autocrine manner, potentially functioning in the differentiation, proliferation or development of beta cells.

Ghrelin has been shown to induce the proliferation of neoplastic cells in certain systems [31], while other studies have demonstrated [2] anti-proliferative or anti-apoptotic effects against neoplastic cells [32]. Ghrelin treatment of pre-adipocytes or motor neurons induced cellular prolifer- 
Fig. 5 Gene expression levels (a) and immunostaining (b-e) of Pdx1 in the pancreases of adult rats. b Quantification of Pdx1 positive cells per unit of total tissue area; c Control group; d Ghrelin group; e n0-STZ group; f n0-STZ/Ghrelin group. Cont Control group, $G$ Ghrelin group, STZ n0-STZ group, $S T Z+G$ n0-STZ/Ghrelin group. Values are expressed as means \pm SEM for four observations in each group. In $\mathbf{c}-\mathbf{f}$, original magnifications were $\times 500 . \quad * p<0.05 ; * * p<0.001$ ( $n=5-8$ rats) a

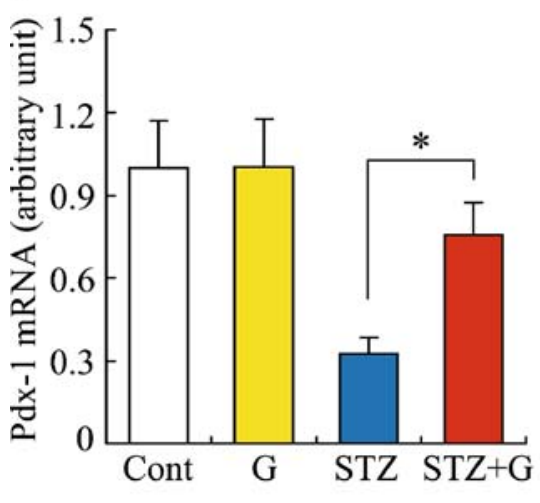

C

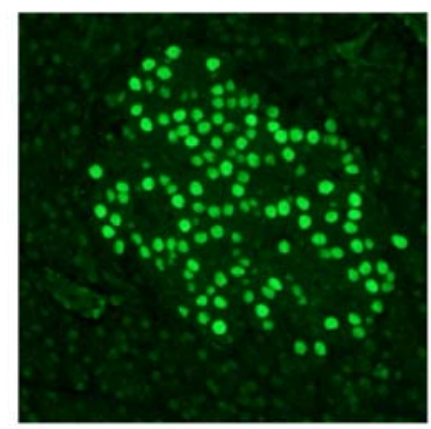

e

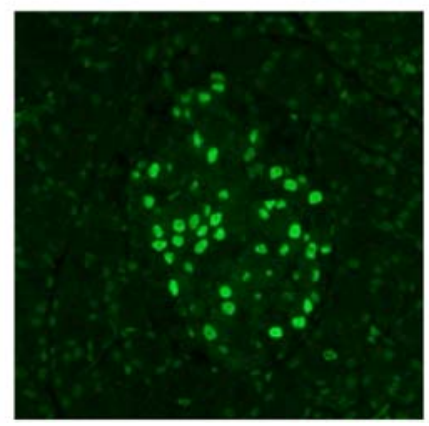

b

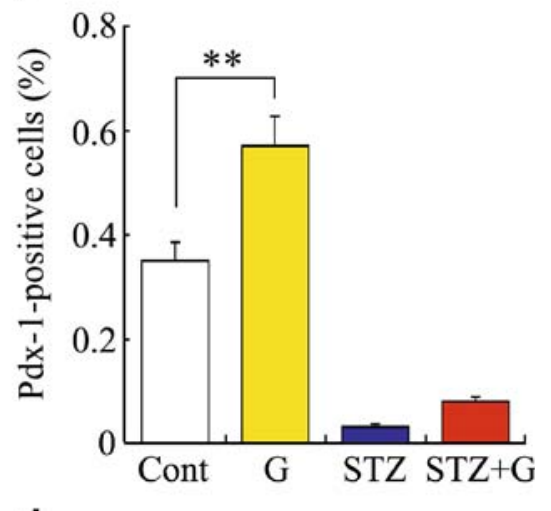

d

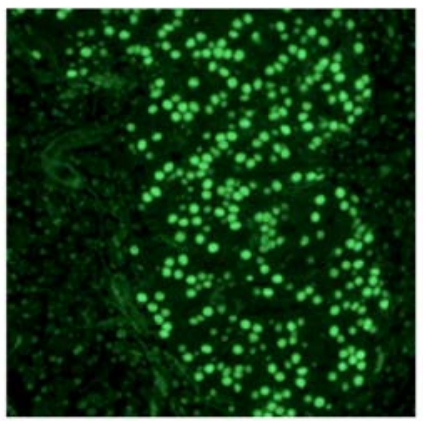

f

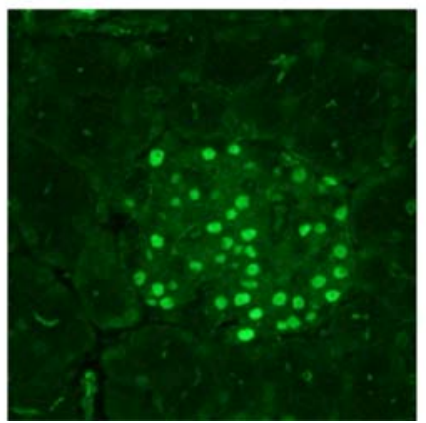

ation and differentiation into mature adipocytes or neurons $[11,12,33]$. While these findings suggest ghrelin may influence cell differentiation, proliferation, development or apoptosis, the mechanism by which ghrelin treatment exerts these effects is not clear. In the present study, expression of $\mathrm{Pdx} 1$, insulin and phospho-histone $\mathrm{H} 3$ in n0STZ/Ghrelin rats was markedly increased in comparison with the level observed in 21-day-old n0-STZ rats. These findings strongly favour the conclusion that ghrelin is stimulating beta cell regeneration or replication in STZtreated newborn rats, although further studies are necessary to clarify the mechanism including the contribution of apoptosis. The values obtained with phospho-histone H3 were higher than those obtained with 5-bromodeoxyuridine (BrdU) staining of beta cells at 21 days in Wistar rats (approximately $0.5-1.5 \%$ ) $[16,24]$. At this moment, we do not clearly know why we obtained higher phospho-histone H3 values in Sprague-Dawley rats of the same age and at 70 days, compared with the BrdU values. Although the correlation between anti-BrdU and -histone labelling indices was statistically significant, variation was noted in the percentage of the BrdU-positive cells doublelabelled with phospho-histone H3, depending on cell type and length of BrdU incubation [34, 35]. Because, as far as we know, no phospho-histone $\mathrm{H} 3$ staining of pancreatic beta cells has been performed, it is difficult to directly compare our results with others. Nonetheless, ghrelin treatment increased the expression level of phosphohistone $\mathrm{H} 3$ at the age of 21 days but not 70 days. Finally, neonatal STZ treatment in earlier studies resulted in a slight increase of beta cell proliferation measured by the BrdU labelling index, in contrast to marked decrease in the present study. This discrepancy will be due to the fact that this neonatal model showed more reduction of pancreatic beta cells compared with other reports, as already discussed.

In addition, it was observed that ghrelin treatment in control rats appeared to result in different alterations from that in STZ-treated rats, for example, regarding body weight and FBG at day 21 and insulin gene expression 
level at day 70. This is probably because physiological and pathological responses to ghrelin treatment are different between healthy control and diabetic STZ-treated rats. Although it is hard to explain these apparent discrepancies at this time, it is necessary to study ghrelin action in healthy controls separately from morbid subjects. Although ghrelin treatment increased body weight in the Ghrelin group compared with the Control group in this study, such a significant difference was not observed in a previous report by Hayashida et al. [36]. However, they also observed that body weight tended to increase after ghrelin treatment, albeit not statistically significantly (personal communication with N. Murakami, Miyazaki University, Miyazaki, Japan). They speculate that the increase in body weight might have reached statistically significance if the number of rats was increased.

From a clinical standpoint, results of the present study suggest that the n0-STZ/Ghrelin rat may be a valuable model to investigate novel treatment strategies for diabetes mellitus. In addition, ghrelin may be a useful treatment for diabetes. Recently, circulating ghrelin levels were discovered to be decreased in patients with type 2 diabetes [37]. Ghrelin activity is involved in insulin resistance as well as the maintenance of energy balance [37]. As multiple studies have demonstrated the importance of ghrelin in glucose and insulin metabolism [2, 3], ghrelin will be an important molecule to investigate the pathophysiology of diabetes.

In conclusion, we have provided evidence that ghrelin may assist the regeneration of beta cells, using STZ-treated newborn rats as a model of diabetes mellitus. In these rats, ghrelin treatment increased pancreatic insulin expression and resulted in the improvement of plasma glucose levels with normal plasma insulin levels. These findings suggest that early administration of ghrelin may prevent the development of diabetes in disease-prone subjects after beta cell destruction.

Acknowledgements We would like to thank H. Hiratani, C. Ishimoto, N. Takehisa and $\mathrm{K}$. Imai for their excellent technical assistance; M. Kouchi and K. Amemiya for their excellent secretarial assistance; and S. Teramukai (Kyoto University, Kyoto, Japan) for his statistical advice. This study was supported by funds from the Ministry of Education, Science, Culture, Sports and Technology of Japan, and the Ministry of Health, Labor, and Welfare of Japan.

\section{References}

1. Kojima M, Hosoda $H$, Date $Y$, Nakazato M, Matsuo $H$, Kangawa K (1999) Ghrelin is a growth-hormone-releasing acylated peptide from stomach. Nature 402:656-660

2. van der Lely AJ, Tschop M, Heiman ML, Ghigo E (2004) Biological, physiological, pathophysiological, and pharmacological aspects of ghrelin. Endocr Rev 25:426-457

3. Korbonits M, Goldstone AP, Gueorguiev M, Grossman AB (2004) Ghrelin - a hormone with multiple functions. Front Neuroendocrinol 25:27-68
4. Lee HM, Wang G, Englander EW, Kojima M, Greeley GH Jr (2002) Ghrelin, a new gastrointestinal endocrine peptide that stimulates insulin secretion: enteric distribution, ontogeny, influence of endocrine, and dietary manipulations. Endocrinology 143:185-190

5. Adeghate E, Ponery AS (2002) Ghrelin stimulates insulin secretion from the pancreas of normal and diabetic rats. J Neuroendocrinol 14:555-560

6. Arosio M, Ronchi CL, Gebbia C, Cappiello V, Beck-Peccoz P, Peracchi M (2003) Stimulatory effects of ghrelin on circulating somatostatin and pancreatic polypeptide levels. J Clin Endocrinol Metab 88:701-704

7. Broglio F, Gottero C, Benso A et al (2003) Effects of ghrelin on the insulin and glycemic responses to glucose, arginine, or free fatty acids load in humans. J Clin Endocrinol Metab $88: 4268-4272$

8. Guan XM, Yu H, Palyha OC et al (1997) Distribution of mRNA encoding the growth hormone secretagogue receptor in brain and peripheral tissues. Brain Res Mol Brain Res 48:23-29

9. Volante M, Allia E, Gugliotta P et al (2002) Expression of ghrelin and of the GH secretagogue receptor by pancreatic islet cells and related endocrine tumors. J Clin Endocrinol Metab 87:1300-1308

10. Chanoine JP, Wong AC (2004) Ghrelin gene expression is markedly higher in fetal pancreas compared to fetal stomach: effect of maternal fasting. Endocrinology 145:3813-3820

11. Kim MS, Yoon CY, Jang PG et al (2004) The mitogenic and anti-apoptotic actions of ghrelin in 3T3-L1 adipocytes. Mol Endocrinol 18:2291-2301

12. Thompson NM, Gill DA, Davies R et al (2004) Ghrelin and des-octanoyl ghrelin promote adipogenesis directly in vivo by a mechanism independent of the type 1a growth hormone secretagogue receptor. Endocrinology 145:234-242

13. Tourrel C, Bailbe D, Meile MJ, Kergoat M, Portha B (2001) Glucagon-like peptide-1 and exendin-4 stimulate beta-cell neogenesis in streptozotocin-treated newborn rats resulting in persistently improved glucose homeostasis at adult age. Diabetes 50:1562-1570

14. Tsuji K, Taminato T, Usami $M$ et al (1988) Characteristic features of insulin secretion in the streptozotocin-induced NIDDM rat model. Metabolism 37:1040-1044

15. Wang RN, Bouwens L, Kloppel G (1994) Beta-cell proliferation in normal and streptozotocin-treated newborn rats: site, dynamics and capacity. Diabetologia 37:1088-1096

16. Wang RN, Bouwens L, Kloppel G (1996) Beta-cell growth in adolescent and adult rats treated with streptozotocin during the neonatal period. Diabetologia 39:548-557

17. Watada H, Kajimoto Y, Miyagawa J et al (1996) PDX-1 induces insulin and glucokinase gene expressions in alphaTC1 clone 6 cells in the presence of betacellulin. Diabetes 45:1826-1831

18. Ferber S, Halkin A, Cohen $\mathrm{H}$ et al (2000) Pancreatic and duodenal homeobox gene 1 induces expression of insulin genes in liver and ameliorates streptozotocin-induced hyperglycemia. Nat Med 6:568-572

19. Kojima H, Nakamura T, Fujita Y et al (2002) Combined expression of pancreatic duodenal homeobox 1 and islet factor 1 induces immature enterocytes to produce insulin. Diabetes 51:1398-1408

20. Matsuoka T, Kajimoto Y, Watada H et al (1995) Expression of CD38 gene, but not of mitochondrial glycerol-3-phosphate dehydrogenase gene, is impaired in pancreatic islets of GK rats. Biochem Biophys Res Commun 214:239-246

21. Petrik J, Reusens B, Arany E et al (1999) A low protein diet alters the balance of islet cell replication and apoptosis in the fetal and neonatal rat and is associated with a reduced pancreatic expression of insulin-like growth factor-II. Endocrinology 140:4861-4873

22. Sun L, Lee J, Fine HA (2004) Neuronally expressed stem cell factor induces neural stem cell migration to areas of brain injury. J Clin Invest 113:1364-1374 
23. Davidson EJ, Morris LS, Scott IS et al (2003) Minichromosome maintenance $(\mathrm{Mcm})$ proteins, cyclin $\mathrm{B} 1$ and $\mathrm{D} 1$, phosphohistone $\mathrm{H} 3$ and in situ DNA replication for functional analysis of vulval intraepithelial neoplasia. Br J Cancer 88:257-262

24. Garofano A, Czernichow P, Breant B (2000) Impaired beta-cell regeneration in perinatally malnourished rats: a study with STZ. FASEB J 14:2611-2617

25. Gnanapavan S, Kola B, Bustin SA et al (2002) The tissue distribution of the mRNA of ghrelin and subtypes of its receptor, GHS-R, in humans. J Clin Endocrinol Metab 87:2988-2991

26. Wierup N, Svensson H, Mulder H, Sundler F (2002) The ghrelin cell: a novel developmentally regulated islet cell in the human pancreas. Regul Pept 107:63-69

27. Broglio F, Gottero C, Benso A et al (2003) Ghrelin and the endocrine pancreas. Endocrine 22:19-24

28. Date Y, Nakazato M, Hashiguchi S et al (2002) Ghrelin is present in pancreatic alpha-cells of humans and rats and stimulates insulin secretion. Diabetes 51:124-129

29. Colombo M, Gregersen S, Xiao J, Hermansen K (2003) Effects of ghrelin and other neuropeptides (CART, MCH, orexin A and $\mathrm{B}$, and GLP-1) on the release of insulin from isolated rat islets. Pancreas 27:161-166

30. Prado CL, Pugh-Bernard AE, Elghazi L, Sosa-Pineda B, Sussel L (2004) Ghrelin cells replace insulin-producing beta cells in two mouse models of pancreas development. Proc Natl Acad Sci USA 101:2924-2929
31. Cassoni P, Ghe C, Marrocco T et al (2004) Expression of ghrelin and biological activity of specific receptors for ghrelin and des-acyl ghrelin in human prostate neoplasms and related cell lines. Eur J Endocrinol 150:173-184

32. Volante M, Allia E, Fulcheri E et al (2003) Ghrelin in fetal thyroid and follicular tumors and cell lines: expression and effects on tumor growth. Am J Pathol 162:645-654

33. Zhang W, Lin TR, Hu Y et al (2004) Ghrelin stimulates neurogenesis in the dorsal motor nucleus of the vagus. J Physiol 559:729-737

34. Gown AM, Jiang JJ, Matles H et al (1996) Validation of the S-phase specificity of histone $(\mathrm{H} 3)$ in situ hybridization in normal and malignant cells. J Histochem Cytochem 44:221-226

35. Muskhelishvili L, Latendresse JR, Kodell RL, Henderson EB (2003) Evaluation of cell proliferation in rat tissues with BrdU, PCNA, Ki-67(MIB-5) immunohistochemistry and in situ hybridization for histone mRNA. J Histochem Cytochem 51:1681-1688

36. Hayashida T, Nakahara K, Mondal MS et al (2002) Ghrelin in neonatal rats: distribution in stomach and its possible role. J Endocrinol 173:239-245

37. Poykko SM, Kellokoski E, Horkko S, Kauma H, Kesaniemi YA, Ukkola O (2003) Low plasma ghrelin is associated with insulin resistance, hypertension, and the prevalence of type 2 diabetes. Diabetes 52:2546-2553 